

\title{
The high sensitivity of InN under rare earth ion implantation at medium range energy
}

B Lacroix, M P Chauvat, P Ruterana, K Lorenz, E Alves, A Syrkin

\section{To cite this version:}

B Lacroix, M P Chauvat, P Ruterana, K Lorenz, E Alves, et al.. The high sensitivity of InN under rare earth ion implantation at medium range energy. Journal of Physics D: Applied Physics, 2011, 44 (29), pp.295402. 10.1088/0022-3727/44/29/295402 . hal-00636199

\section{HAL Id: hal-00636199 \\ https://hal.science/hal-00636199}

Submitted on 27 Oct 2011

HAL is a multi-disciplinary open access archive for the deposit and dissemination of scientific research documents, whether they are published or not. The documents may come from teaching and research institutions in France or abroad, or from public or private research centers.
L'archive ouverte pluridisciplinaire HAL, est destinée au dépôt et à la diffusion de documents scientifiques de niveau recherche, publiés ou non, émanant des établissements d'enseignement et de recherche français ou étrangers, des laboratoires publics ou privés. 


\title{
The high sensitivity of InN under rare earth ion implantation at medium range energy
}

 \\ ${ }^{1}$ Centre de Recherche sur les Ions, les Matériaux et la Photonique, UMR 6252 CNRS- \\ ENSICAEN-CEA-UCBN, 6, Boulevard du Maréchal Juin, 14050 Caen Cedex, France \\ ${ }^{2}$ Instituto Tecnológico e Nuclear, EN 10, 2686-953 Sacavém, Portugal \\ ${ }^{3}$ Technologies and Devices International, an Oxford Instruments Company, 12214 Plum \\ Orchard Dr. Silver Spring, MD 20904, USA
}

\begin{abstract}
In this work, the damage formation in $\mathrm{InN}$ layers has been investigated subsequent to europium implantation at $300 \mathrm{keV}$ and room temperature. The layers of several microns were produced by Hydride Vapour Phase Epitaxy and used as matrices for ion implantation experiments due to their good crystalline quality. From this investigation, it is shown that InN exhibits a low stability under rare earth ion implantation. Starting at a low fluence of around $5 \times 10^{12} \mathrm{Eu} / \mathrm{cm}^{2}$, an extensive modification of the surface layer takes place. The dissociation of InN and the presence of misoriented nanograins are observed in the damaged area. Analysis by electron diffraction indicates that the nanograins correspond to indium oxide $\operatorname{In}_{2} \mathrm{O}_{3}$.
\end{abstract}

Keywords: InN, ion implantation, TEM, rare earth 


\section{Introduction}

For the last two decades, the group of III-V nitride semiconductors (AlN, GaN and $\mathrm{InN}$ ) has been intensively investigated owing to their high technological application potential in micro- and opto-electronics [1,2]. In the semiconductor technology, ion implantation is extensively used to tune the properties and functionalities of materials. It offers a wide range of energies and constitutes an interesting tool to perform dry etching, ion cut, electrical isolation, and to introduce electrically and optically active dopants below the surface. In particular, for gallium nitride, ion implantation at medium range energy (one to a few hundred $\mathrm{keV}$ ) has attracted much attention to investigate the $\mathrm{n}$ or $\mathrm{p}$ doping with $\mathrm{Si}$ or $\mathrm{Mg}$ species, but also to incorporate optically active rare earth elements $[3,4]$. Thus, the literature about ion implantation and correlated irradiation effects on $\mathrm{GaN}$ is becoming more and more complete [5-7]. In particular, the mechanisms of damage formation have been shown to differ from the conventional scheme of amorphization [8-11]. In the case of AlN, only a few reports are available on electronic quality layers, as was shown, this material is resistant to ion implantation damage formation and the amorphization has been shown to take place at very high implantation fluences $\left(\sim 10^{17}\right.$ at./ $\left./ \mathrm{cm}^{2}\right)$ [12]. As for InN, despite its potential practical importance, data on the effect of ion implantation and irradiation are still scarce. During the last decade, important advances have been made on $\mathrm{InN}$ growth, and its band gap has been redefined from the earlier of $1.89 \mathrm{eV}$ to $0.67 \mathrm{eV}$ using layers grown by molecular beam epitaxy [13,14] where layers thickness of up to $10 \mu \mathrm{m}$ have been grown [15]. Up to now, successful growth has also been reported by metalorganic vapour phase epitaxy [16,17] and the highest rates for this substantially low temperature growth material is now achieved by hydride vapor phase epitaxy (HVPE), where some $4 \mu \mathrm{m} / \mathrm{h}$ growth rates can be obtained around $500^{\circ} \mathrm{C}$ [18]. In the following, we report on the investigation of the damage formation in HVPE InN layers subsequent to Eu ion implantation at $300 \mathrm{keV}$. In contrast to $\mathrm{GaN}$ and $\mathrm{AlN}$, 
where highly efficient dynamic annealing has been reported $[3,5]$ and severe damage in form of nanocrystallization $(\mathrm{GaN})$ [9-11] or amorphization (AlN) [12] occurs only at substantially higher fluences, it is shown that the implantation of these heavy rare earth ions, strongly damages $\mathrm{InN}$ at very low fluences, starting in the $10^{12}$ at. $/ \mathrm{cm}^{2}$ range.

\section{Experimental}

Indium nitride ( $\mathrm{InN})$ was grown on a (0001) gallium nitride $(\mathrm{GaN})$ buffer layer deposited on (0001) sapphire by hydride vapor phase epitaxy. InN was then implanted at room temperature with europium $(\mathrm{Eu})$ ions at $300 \mathrm{keV}$. The mean projected range, $R p$, the straggling, $\Delta R p$, and the position of the maximum of damage from the surface are $60 \mathrm{~nm}, 24$ $\mathrm{nm}$, and $38 \mathrm{~nm}$, respectively (using Monte-Carlo SRIM calculations [19]). Structural investigations were conducted through transmission electron microscopy (TEM) experiments. Cross-section samples were thinned down to less than $10 \mu \mathrm{m}$ by mechanical polishing using the tripod method. The electron transparency was achieved by ion milling at $5 \mathrm{kV}$ using the GATAN precision ion polisher system (PIPS) at an incidence angle of $5^{\circ}$ with the sample holder kept at $150 \mathrm{~K}$ in order to minimize the beam damage to the samples. Observations were carried out by conventional and high resolution transmission electron microscopy in JEOL 2010 (CTEM) and JEOL 2010F (HRTEM) microscopes operated at $200 \mathrm{keV}$.

\section{Results}

In order to determine the TEM sample preparation effects on the $\mathrm{InN}$ layer structure, we have first made observations on a reference InN layer, from the same wafer, which has not undergone ion implantation. Its microstructure is shown in figure 1. As can be noticed, the InN layer has a relatively large surface roughness with a peak to peak extension of about 100 $\mathrm{nm}$. The dislocations which have a $c$ character slightly bend at the $\mathrm{InN} / \mathrm{GaN}$ interface and 
cross the InN layer to the surface as shown in the $\mathbf{g}=0002$ weak beam image of figure $1(\mathrm{a})$. The $\mathbf{g}=1100$ weak beam image of the same area shows other interesting features (figure 1(b)). As can be seen, most of the threading dislocations in the GaN buffer layer are of mixed type $1 / 3<11 \overline{2} 3>$. Moreover, the surface morphology appears to be connected to new networks of edge and mixed type dislocations which have been generated at the InN/GaN interface. This contrast in figure 1(b) is clearly indicative of domain growth with various small rotations around the $c$ axis [20] from mosaic growth of $\mathrm{InN}$ on $\mathrm{GaN}$ which have large differences in $a$ parameter. Each domain contains a high density of basal stacking faults (BSFs) which extend until the surface. This is in contrast to the growth of GaN where the SFs are mainly localized close to the interface with the sapphire substrate [21]. In the case of InN, the SFs extension towards the surface is mediated by prismatic stacking faults (PSFs) [22,23] which are also in contrast with $\mathbf{g}=1 \overline{100}$ (figure $1(\mathrm{~b})$ ).

After implantation at $5 \times 10^{12} \mathrm{Eu} / \mathrm{cm}^{2}$, the surface layer of the wafer is dramatically modified to a depth of around 110 to $130 \mathrm{~nm}$ (figure 2). In the dark field images acquired with $\mathbf{g = 0 0 0 2}$ (figure 2(a)) and $\mathbf{g}=1100$ (figure 2(b)), the highly damaged areas exhibits three different contrasts as have been labelled A, B and C. The B layer, which corresponds to the highest concentration of the damage, exhibits a dark contrast and follows, as would be expected, the surface morphology. This dark buried layer is centred on $R p$ and it is embedded between the bright $\mathrm{A}$ and $\mathrm{C}$ areas which are defective but exhibit a monocrystalline contrast. As can be noticed by comparing figure 1 and figure 2, the defects which were observed immediately after the growth all along the InN layer (dislocations and SFs) are now interrupted by the damaged layer formed during implantation at the initiation of layer B.

As shown along the [1120 ] zone axis micrograph of figure 3, the B area structure completely differs from A and C. It contains bright and dark contrasts of various shapes and extensions (their lateral size can reach 30 to $50 \mathrm{~nm}$ ). The HRTEM images acquired in the implanted layer 
(figure 4(a) and figure 4(b)) reveal that: (i) the A region at the surface is crystalline, (ii) the B layer is highly damaged and it contains small misoriented nanograins surrounded by large bright areas which could be ascribed either to amorphous pockets, voids or $\mathrm{N}_{2}$ gas bubbles due to InN dissociation. We can notice the presence of Moiré fringes (labelled $m$ ) in the B layer which indicate the overlap of grains with different orientations. The corresponding diffraction pattern is displayed in figure 5(a): it contains both spots of $\mathrm{InN}$ and additional coarser and distorted spots whose positions do not match perfectly with the InN wurtzite structure (see for example the $S_{1}, S_{2}, S_{3}, S_{4}, S_{5}, S_{6}$ and $S_{7}$ spots indicated by white arrows). These extra spots might have various origins: (i) Are they related to less stable InN polytypes such as the zinc-blende phase or the high pressure rocksalt structure? (ii) Can they be ascribed to the formation of metallic In due to the In-N dissociation? (iii) Can they be related to indium oxide $\left(\operatorname{In}_{2} \mathrm{O}_{3}\right)$ subsequent to the oxidation of metallic In when the sample is removed from the implantation chamber, as was previously proposed by Timmers et al. [24]? To check these assumptions, powder diffraction patterns of the above structures have been simulated using the JEMS software [25] and compared to the experimental SAED pattern which was acquired close to the interface between the implanted and the non-implanted layer, in order to get a reliable reference from the undamaged $\mathrm{InN}$ crystal.

As would be expected, all the fine spots observed on the diffraction pattern are related to the InN wurtzite structure. However, this phase as well as the pure metallic In tetragonal phase or the InN rocksalt structure are not able to describe satisfactorily the coarse and distorted spots indicated by $S_{1}, S_{2}, S_{3}, S_{4}$ and $S_{5}$ (simulations not shown here). The simulations of the cubic InN zinc-blende and the $\operatorname{In}_{2} \mathrm{O}_{3}$ structures lead to a better description of the diffraction pattern: the $S_{1}, S_{2}, S_{4}$ and $S_{5}$ spots can be related to the (111), (111), (002) and (220) reflections of the InN zinc-blende phase, and/or to the (222), (22) $)$, (004) and (440) reflections of $\operatorname{In}_{2} \mathrm{O}_{3}$, respectively, both structures being viewed along the [110] zone axis. Moreover, the angles 
between these spots are consistent with the cubic symmetry: for example, for cubic $\operatorname{In}_{2} \mathrm{O}_{3}$ the angle relationship between the (222) planes and the (22) $),(004)$ and (440) are about $70^{\circ}, 55^{\circ}$ and $35^{\circ}$, respectively. Nevertheless, the $S_{3}$ weak spot, which is inclined by $90^{\circ}$ from the $S_{1}$ spot, but also the $S_{6}$ and $S_{7}$ can only be identified as the (1112), (226) and ( $\left.\overline{2} \overline{2} 6\right)$ reflections of $\mathrm{In}_{2} \mathrm{O}_{3}$. Obviously, by symmetry, the grains rotate by $70^{\circ}$ around the [110] zone axis to keep the other $\{111\}$ planes parallel to the surface, but also the in-plane grains rotation by $180^{\circ}$ enable to fully explain the presence of the other spots in figure 5(b). Therefore, the very good agreement between simulated and experimental diffraction patterns shows that cubic $\operatorname{In}_{2} \mathrm{O}_{3}$ is present in the implanted area.

To localize the different phases which have been identified above, a detailed HRTEM analysis of the near surface image (Fig 4(a)) was performed (not shown here). By filtering the Fourier image with specific spots, this study indicates that the crystalline A region may correspond to a wurtzite phase, whereas the small misoriented nanograins in the B layer are related to the $\mathrm{InN}$ zinc-blende and the $\mathrm{In}_{2} \mathrm{O}_{3}$ bixbyite structures. Rutherford backscattering spectrometry measurements (not shown) on the same implanted layers furthermore show a strong change in stochiometry within the implanted region in agreement with the existence of $\mathrm{In}_{2} \mathrm{O}_{3}$ and confirming that the observed results are not caused by the TEM sample preparation.

\section{Discussion}

This work clearly shows that $\mathrm{InN}$ is very sensitive to the damage induced by the rare earth ion beam at medium range energy. A high degree of disorder is observed close to the surface after

implantation at very low fluence $\left(5 \times 10^{12} \mathrm{Eu} / \mathrm{cm}^{2}\right)$, within a layer of about 110 to $130 \mathrm{~nm}$ in width: while the first 10 to $20 \mathrm{~nm}$ remain crystalline, the underlying layer exhibits a much more complex microstructure. The latter is composed of small misoriented nanograins whose structure is shown to be different from InN. Within this detailed investigation of the electron 
diffraction patterns, we have been able to extract more information about the structure of these nanograins. The simulations of the most probable expected phases indicate that those grains exhibit the $\operatorname{In}_{2} \mathrm{O}_{3}$ bixbyite structure. Moreover, in the highly damaged layer, large bright areas have formed and they can be identified either as amorphous pockets, voids or $\mathrm{N}_{2}$ gas bubbles resulting from the dissociation of $\mathrm{InN}$ (breaking of the In-N bonds). Significant nitrogen depletion in $\mathrm{InN}$ was previously observed by different authors after irradiation, implantation or ion beam analysis experiments [26-29] but also after annealing at around $550^{\circ} \mathrm{C}$ [30]. Thus, in our case, a nitrogen release seems to be the most probable phenomenon. This nitrogen loss should be accompanied by a stoichiometry modification, which is in contradiction with the assumption of a wurtzite to zinc-blende phase transformation. Instead, InN dissociation could explain the presence of indium oxide nanograins in the $\mathrm{N}$-depleted region. It may be expected that an important $\mathrm{N}$ depletion leads to the formation of metallic In clusters. Then, as proposed in Ref. [24], oxidation of the metallic In phase could occur when the sample is removed from the implantation chamber to air. Indeed, because the heat formation at room temperature of $\operatorname{In}_{2} \mathrm{O}_{3}(-221.27 \mathrm{kcal} / \mathrm{mol})$ is significantly lower than $\mathrm{InN}$ ($4.2 \mathrm{kcal} / \mathrm{mol}$ ) [31], indium would exhibit a stronger preference to the oxidation process.

During rare earth implantation in the same conditions, the fluence range leading to the breakdown of the wurtzite structure of $\mathrm{GaN}$ and $\mathrm{AlN}$ is about three to five orders of magnitude higher than for $\mathrm{InN}$, and it was shown that the damage build-up is driven by the formation of a dense network of extended defects (mainly basal stacking faults). For GaN, the formation of a nanocrystalline layer from the surface occurs above $2 \times 10^{15} \mathrm{Eu} / \mathrm{cm}^{2}$, when the stacking fault network has reached the surface [10,11]. For AlN, the stacking fault network does not reach the surface and an amorphization in the bulk, around $R p$, has been reported for fluences higher than $10^{17} \mathrm{Eu} / \mathrm{cm}^{2}[12]$. 
The high resistance to amorphization of $\mathrm{GaN}$ and $\mathrm{AlN}$ has been ascribed to an efficient dynamic annealing during implantation [32,33] which enables the defect annihilation and the arrangement into an array of planar defects. In absence of dynamic annealing, the damage accumulation leads to a complete lattice disordering or to amorphization when each atom has been moved approximately one time (1 displacement per atom (dpa)). For example, amorphization in silicon was reported at a fluence of $7 \times 10^{13} \mathrm{Eu} / \mathrm{cm}^{2}$ after implantation at 300 $\mathrm{keV}$ and $\mathrm{RT}$ at a maximum of damage close to $0.8 \mathrm{dpa}$ [34].

In an attempt to explain this behaviour, we also carried out SRIM calculations of the damage and ion profiles for the implantation at $5 \times 10^{12} \mathrm{Eu} / \mathrm{cm}^{2}$ and $300 \mathrm{keV}$. In their report on this material, Mkhoyan and Silcox [27] pointed out that InN, with its cohesive energy per bond of about $1.9 \mathrm{eV}$, should have a surface binding energy between 5-6 eV and its bulk displacement energy should be approximately five times higher. So, displacement energies $\left(E_{d}\right)$ of $25 \mathrm{eV}$ for both In and $\mathrm{N}$ were used, and this led to very low calculated values of $0.05 \mathrm{dpa}$ and 0.001 $\%$ atomic fraction, respectively. This maximum of damage ( $0.05 \mathrm{dpa})$ is far from $1 \mathrm{dpa}$ which may indicate that the structural breakdown of $\mathrm{InN}$ is probably not dominated by nuclear interactions (ballistic collisions).

In their work on InGaN alloys, Kucheyev et al. [33] pointed out the detrimental effect of indium on the structure stability, and they showed that an increase of the In content degrades the dynamic annealing efficiency during the ion implantation. They related the lower dynamic annealing efficiency of the III-N semiconductors containing indium to the lower In-N binding energy, in comparison with the Ga-N or Al-N binding energies. For InN, GaN and AlN, the cohesive energies $\left(E_{c}\right)$ are $E_{c}^{I n N}=7.970 \mathrm{eV} /$ atom, $E_{c}^{G a N}=9.058 \mathrm{eV} /$ atom and $E_{c}^{A I N}=11.669$ eV/atom, respectively: these values correspond to experimental data reported in Ref. [35], and then reported after correction by phonon zero-point energies and by atomic spin-orbit splitting in Refs. [36-37]. In addition to the energetic aspect of the atomic bonds, it is also particularly 
interesting to consider the formation enthalpies of these III-N semiconductors, which bring essential information about their thermodynamical stability. Indeed, by comparison with AlN and $\mathrm{GaN}$, the wurtzite structure of $\mathrm{InN}$ exhibits a significantly lower formation enthalpy $\left(\Delta H_{f}\right)$, of about one range of magnitude $\left(\Delta H_{f}^{I n N}=-0.21 \mathrm{eV}, \Delta H_{f}^{G a N}=-1.08 \mathrm{eV}\right.$ and $\Delta H_{f}^{A l N}=-$ $3.13 \mathrm{eV}$ ) [38] which means that $\mathrm{InN}$ is not as stable as GaN or AlN. Several studies have also been devoted to the calculations of the cohesive energies and the formation enthalpies of the nitride semiconductors. In particular, Zoroddu et al. [37] have performed density-functional calculations, using the LDA and GGA methods, to predict the physical properties (values from the literature are reported in Table II). For the III-V nitrides, the calculations concluded to a stable wurtzite structure as experimentally observed, and it was shown that the GGA method led to a better agreement with the experimental results than LDA for AlN and GaN. The same authors also calculated the formation enthalpies and reported a very good match with experiments for AlN and GaN using the GGA. However, surprisingly, the GGA calculations of $\Delta H_{f}$ for InN gave a small but positive value which led the authors to conclude that InN may be thermodynamically unstable [37].

\section{Conclusion}

From the above observations, it is clear that $\mathrm{InN}$ is not stable during rare earth implantation at very low fluences $\left(5 \times 10^{12} \mathrm{Eu} / \mathrm{cm}^{2}\right)$. Interestingly, the damage formation follows a conventional distribution and the crystalline system breaks down around $R p$, where the concentration of implanted ion is the highest and where the largest part of atomic displacements occurs. In the damaged area, both $\mathrm{InN}$ dissociation and presence of indium oxide nanograins are evidenced. From the SRIM simulations, these fluences correspond to negligible displacements $(0.05 \mathrm{dpa})$ and very low rare earth concentrations $(0.001 \%)$. This is 
an indication that the ballistic effects may not be dominant and it points to the fact that indium nitride may exhibits an intrinsic metastable character, as appears to have been deduced from previous GGA calculations. These results need now to be confirmed, and in particular, in situ experiments are in progress in order to determine the origin of the observed $\operatorname{In}_{2} \mathrm{O}_{3}$.

\section{Acknowledgment}

The authors acknowledge the support of the 'Région Basse Normandie' and of FCT Portugal (Ciência 2007 and PTDC/CTM/100756/2008) to this research work.

\section{References}

[1] Nakamura S and Fasol G 2000 The Blue Laser Diode (Springer, New York)

[2] Morkoc H 2008 Handbook of Nitride Semiconductors and Devices vol. 3 (Wiley-VcH, Berlin)

[3] Pearton S J, Ren F, Zhang A P and Lee K P 2000 Mater. Sci. Eng. R. 3055

[4] Mamor M, Matias V, Vantomme A, Colder A, Marie P and Ruterana P 2004 Appl. Phys. Lett. 852244

[5] Kucheyev S O, Williams J S, Jagadish C, Zou J, and Li G 2000 Phys. Rev. B 627510

[6] Lorenz K, Barradas N P, Alves E, Roqan S, Nogales E, Martin R W, O’Donnell K P, Gloux F and Ruterana P 2009 J. Phys. D Appl. Phys. 42165103

[7] Kucheyev S O, Williams J S and Pearton S J 2001 Mater. Sci. Eng. R 3351

[8] Ding F-R, He W-H, Vantomme A, Zhao Q, Pipeleers B, Jacobs K and Moerman I 2003 Mat. Sci. Semicon. Processing 5511

[9] Bae I T, Jiang W, Wang C, Weber W J and Zhang Y 2009 J. Appl. Phys. 10583514

[10] Gloux F, Wojtowicz T, Ruterana P, Lorenz K and Alves E 2006 J. Appl. Phys. 100 073520

[11] Ruterana P, Lacroix B and Lorenz K 2011 J. Appl. Phys. 109013506 
[12] Lorenz K, Alves E, Gloux F, Ruterana P, Peres M, Neves A J and Monteiro T $2010 \mathrm{~J}$. Appl. Phys. 107023525

[13] Davydov V Y et al. 2002 Phys. Stat. Sol. (b) 230 R4

[14] Davydov V Y et al. 2002 Phys. Stat. Sol. (b) 234, 787

[15] Liu B et al. 2008 J. Appl. Phys. 10323540

[16] Ruterana P, Abouzaid M, Gloux F, Maciej M, Doualan J L, Drago M, Schmidtling T, Pohl U W and Richter W 2006 Phys. Stat. Sol. (a) 203158

[17] Lozano J G, Sánchez A M, García R, Gonzalez D, Briot O and Ruffenach S 2006 Appl. Phys. Lett. 88, 151913

[18] Ruterana P, Syrkin A L, Monroy E, Valcheva E and Kirilov K 2010 Phys. Stat. Sol. (c) 71301

[19] Ziegler J F, Biersack J P and Littmark U 1985 The Stopping and Range of Ions in Solids (Pergamon, New York)

[20] Potin V, Ruterana P, Nouet G, Pond R C and Morkoç H 2000 Phys. Rev. B 615587

[21] Potin V, Ruterana P and G. Nouet 2000 J. Phys.: Condens. Matter. 1210301

[22] Potin V, Vermaut P, Ruterana P and Nouet G 1998 J. Electron. Mater. 27266

[23] Vermaut P, Nouet G and Ruterana P 1999 Appl. Phys Lett. 74694

[24] Timmers H, Shrestha S K and Byrne A P 2004 J. Cryst. Growth 26950

[25] Stadelmann P A 1987 Ultramicroscopy 21131

[26] Emtsev V V, Davydov V Y, Haller E E, Klochikhin A A, Kozlovskii V V, Oganesyan G A, Poloskin D S, Shmidt N M, Vekshin V A and Usikov A S 2001 Physica B: Condens. Matter 308-310 58

[27] Mkhoyan K A and Silcox J 2003 Appl. Phys. Lett. 82859

[28] Kosiba R, Ecke G, Cimalla V, Spie L, Krischok S, Schaefer J A, Ambacher O and Schaff W J 2004 Nucl. Instrum. Methods B 215486 
[29] Shrestha S K, Timmers H, Butcher K S A, Wintrebert-Fouquet M and Chen P P-T 2005 Nucl. Instrum. Methods B 234291

[30] Guo Q, Kato O and Yoshida A 1993 J. Appl. Phys. 737969

[31] Weast R C 1983-1984 CRC Handbook of Chemistry and Physics (Florida: Academic)

[32] Williams J S 1998 Mater. Sci. Eng. A 2538

[33] Kucheyev S O, Williams J S, Zou J and Jagadish C 2004 J. Appl. Phys. 953048

[34] Gloux F, Ruterana P, Lorenz K and Alves E 2008 Phys. Stat. Sol. (a) 20568

[35] Harrison W A 1989 Electronic Structure and the Properties of Solids (Dover, New York)

[36] Paulus B, Shi F-H and Stoll H 1997 J. Phys. Condens. Matter 92745

[37] Zoroddu A, Bernardini F, Ruggerone P and Fiorentini V 2001 Phys. Rev. B 64, 045208

[38] Parsons R 1967 D’Ans-Lax Taschenbuch für Chemiker und Physiker, Band I, ed E Lax and C Synowietz (Springer, Berlin)

[39] Bhuiyan A G, Hashimoto A and Yamamoto A 2003 J. Appl. Phys. 942779

[40] Serrano J, Rubio A, Hernandez E, Munoz A and Mujica A 2000 Phys. Rev. B 6216612

[41] Smith J and Schneider V 1964 J. Less Common Met. 717

[42] Fuchs F and Bechstedt F 2008 Phys. Rev. B 77155107 
TABLES

\begin{tabular}{|c|c|c|c|c|}
\hline Phase & $\begin{array}{c}\text { Symmetry } \\
\text { (Structure type) }\end{array}$ & Space group & $\begin{array}{c}\text { Lattice parameter } \\
(\AA)\end{array}$ & Ref. \\
\hline InN & $\begin{array}{l}\text { Hexagonal } \\
\text { (Wurtzite) }\end{array}$ & P63mc & $\begin{array}{c}a=b=3.5365 \\
c=5.7039\end{array}$ & [39] \\
\hline $\mathrm{InN}$ & $\begin{array}{c}\text { Cubic } \\
\text { (Zinc-Blende) }\end{array}$ & $\mathrm{F} 43 \mathrm{~m}$ & $a=4.98$ & [39] \\
\hline $\mathrm{InN}$ & $\begin{array}{c}\text { Cubic } \\
\text { (Rocksalt) }\end{array}$ & $\mathrm{Fm} \overline{3} \mathrm{~m}$ & $a=4.636$ & [40] \\
\hline In & Tetragonal & $\mathrm{I} 4 / \mathrm{mmm}$ & $\begin{array}{c}a=b=4.5912 \\
c=4.9355\end{array}$ & [41] \\
\hline $\mathrm{In}_{2} \mathrm{O}_{3}$ & $\begin{array}{c}\text { Cubic } \\
\text { (Bixbyite) }\end{array}$ & $\mathrm{Ia} \overline{3}$ & $a=10.094$ & [42] \\
\hline
\end{tabular}

TABLE I. Structural parameters used for powder diffraction simulations of the different expected phases in the damaged layer.

\begin{tabular}{llccc}
\hline & & AIN & GaN & InN \\
\hline \multirow{3}{*}{$E_{c}(\mathrm{eV} /$ atom) } & Exp. & 11.669 & 9.058 & 7.970 \\
& Calc. (LDA) & 13.536 & 10.999 & 9.249 \\
& Calc. (GGA) & 12.071 & 9.265 & 7.695 \\
\hline \multirow{3}{*}{$\Delta H_{f}(\mathrm{eV})$} & Exp. & -3.13 & -1.08 & -0.21 \\
& Calc. (LDA) & -3.642 & -1.685 & -0.303 \\
& Calc. (GGA) & -3.142 & -1.102 & 0.125 \\
\hline
\end{tabular}

TABLE II. Cohesive energy, $E_{c}$, and formation enthalpy, $\Delta H_{f}$, for wurtzite AlN, GaN and InN, from Refs. [36-38]. 


\section{Figures captions}

FIG. 1. Cross-section view of the as-grown InN layer using (a) $\mathbf{g}=0002$ and (b) $\mathbf{g}=1 \overline{100}$ weak beam conditions.

FIG. 2. Cross-section view of the InN layer after Eu implantation at $5 \times 10^{12} \mathrm{Eu} / \mathrm{cm}^{2}$ using (a) $\mathbf{g}=0002$ and (b) $\mathbf{g}=1 \overline{1} 00$ weak beam conditions.

FIG. 3. Cross-section view of the InN layer, viewed along the [1120] zone axis, after Eu implantation at $5 \times 10^{12} \mathrm{Eu} / \mathrm{cm}^{2}$. Bright areas of various shape and size are evidenced in the damaged area.

FIG. 4. HRTEM performed along the $[11 \overline{2} 0]$ zone axis of $\mathrm{InN}$ in the implanted region after $5 \times 10^{12} \mathrm{Eu} / \mathrm{cm}^{2}$ implantation, (a) close to the surface and (b) in the highly damaged layer. Moiré fringes, labelled by $m$, are visible.

FIG. 5. Diffraction patterns of the damaged area of InN, after Eu implantation. (a) Some unexpected and unidentified spots $\left(S_{1}, S_{2}, S_{3}, S_{4}, S_{5}, S_{6}\right.$ and $\left.S_{7}\right)$ are indicated by white arrows on the experimental diffraction pattern. (b) Simulation of the diffraction pattern of cubic (bixbyite) structure of $\mathrm{In}_{2} \mathrm{O}_{3}$. The dotted rings correspond to the most intense reflections. Some new spots are identified with respect to the [110] zone axis, with the (111) planes parallel to the surface. The other spots are easily deduced by $70^{\circ}$ rotation around [110] to keep the other $\{111\}$ planes parallel to the surface. 


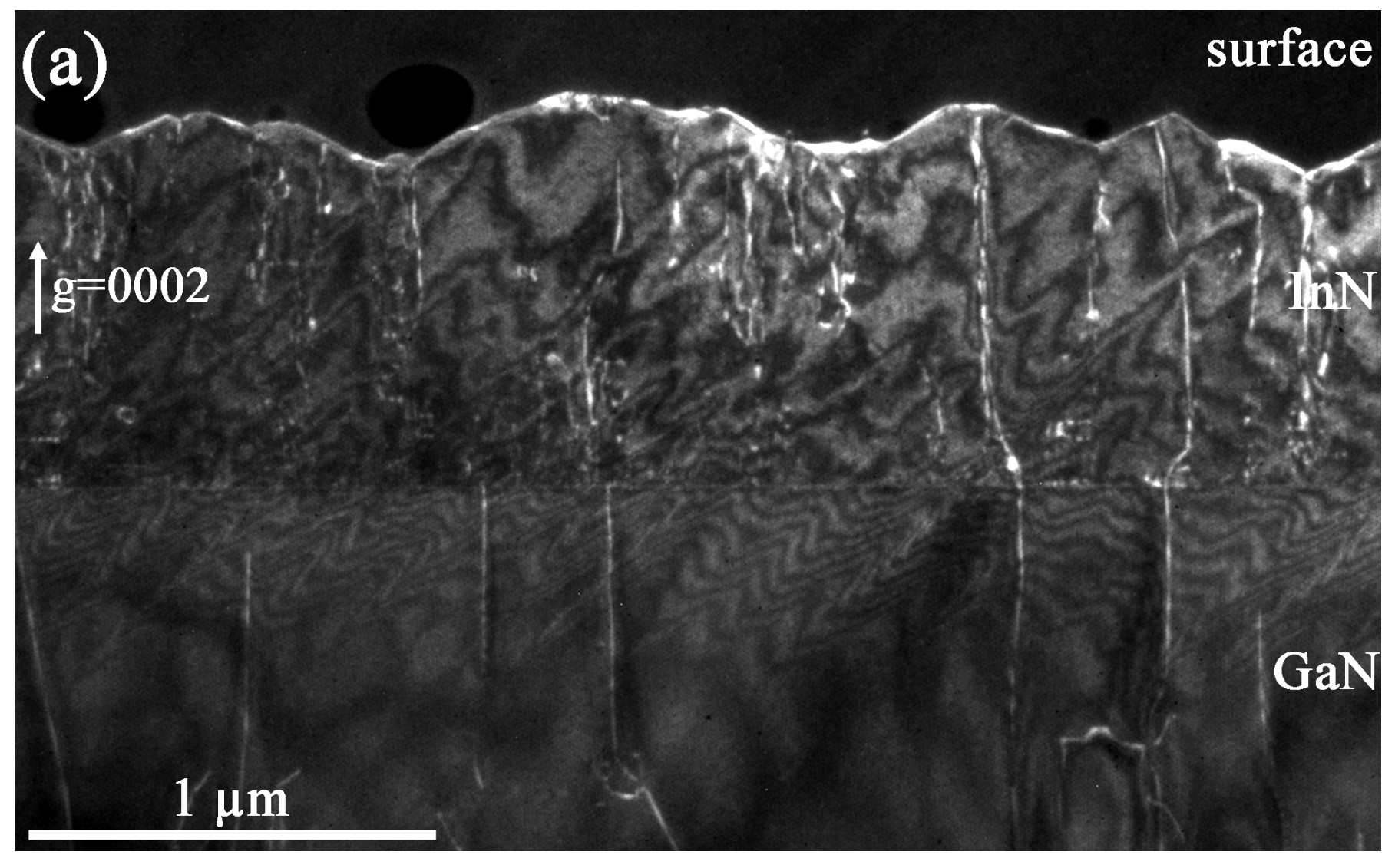

Figure 1a (Figure1a.tif) 




Figure 1b (Figure1b.tif) 




Figure 2a (Figure2a.tif) 


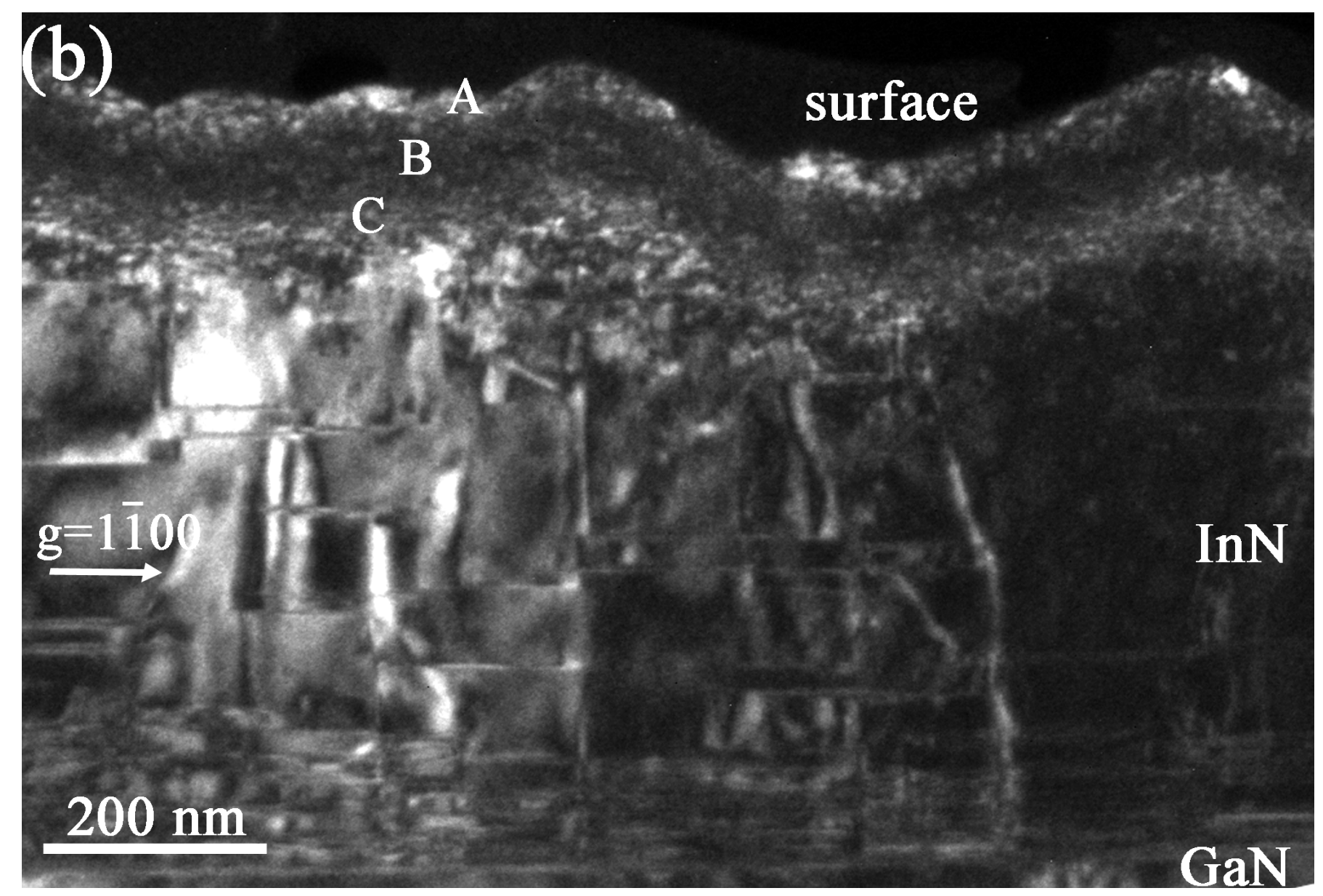

Figure 2b (Figure2b.tif) 




Figure 3 (Figure3.tif) 




Figure 4a (Figure4a.tif) 


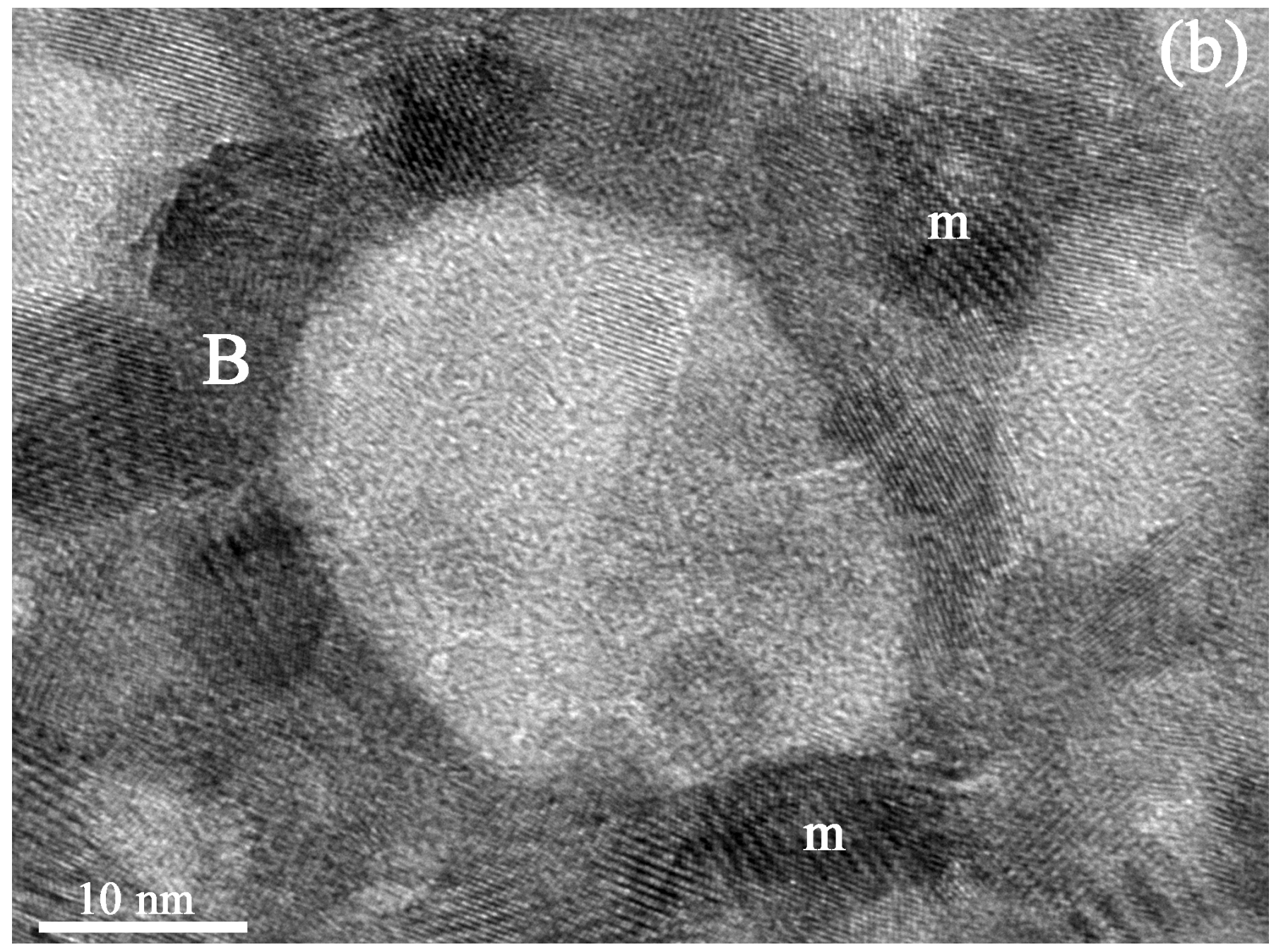

Figure 4b (Figure4b.tif) 




Figure 5a (Figure5a.tif) 




(b)

Figure 5b (Figure5b.tif) 